\title{
Bullying Among Lower Secondary School Students in Pattani Province, Southern Thailand
}

\author{
Boonyapat Yodprang \\ Department of Mathematics and Computer Science \\ Faculty of Science and Technology, Prince of Songkla University, Pattani \\ Tel: 66-89-881-2487 E-mail: y_boonyapat@hotmail.com \\ Metta Kuning \\ Department of Mathematics and Computer Science \\ Faculty of Science and Technology, Prince of Songkla University, Pattani \\ E-mail:kmetta@bunga.pn.psu.ac.th \\ Nittaya McNeil \\ Department of Mathematics and Computer Science \\ Faculty of Science and Technology, Prince of Songkla University, Pattani
}

\begin{abstract}
This study aimed to investigate the prevalence of physical bullying and to identify a suitable statistical model accounting for risk factors affecting physical bullying among lower secondary school students in Pattani province, southern Thailand. A cross-sectional survey was conducted among 244 students aged 12 to 19 years by questionnaire. All participants were interviewed in December 2006 in a neutral location outside the schools. Questions on physical bullying referred to behaviour during both the preceding six months and during the previous month. Pearson's chi-squared test was used to assess the associations between the outcome and various determinants. Logistic regression was used to identify risk factors for physical bullying. The overall prevalence of physical bullying was found to be $18.5 \%$ (95\% CI: 13.6-23.4). Gender was not significantly associated with bullying others. The outcome was associated to a statistically significant degree with age group, ethnicity, school type and parental violence. Specifically, the results from this study indicated that students who had experience of parental violence were more likely to be bullies at school.
\end{abstract}

Keywords: Bullying, Physical abuse, Parental violence

\section{Introduction}

Bullying in schools is a problem in many countries around the world. It occurs in all schools at all grade levels, although most frequently at the elementary level (Sampson, 2002). Bullying affects a significant number of children and adolescents in all schools. In many countries, it is an issue of growing concern to parents, teachers, and social workers. Research on the prevalence of school bullying has occurred in diverse settings in many countries. Based on interviews in the United States, DeVoe and Kaffenberger (2005) indicated that the prevalence of physical bullying was found to be $8 \%$ among students aged 12-18 years during the preceding six months. Portugal by Pereira et al, (2004) reported that approximately $20 \%$ of students had been bullied and around $16 \%$ of them admitted having bullied others at least three times during the term. A study in Hong Kong reported that $17.2 \%$ of secondary school students admitted bullying other at some time during the previous six months (Wong, 2004). In addition, a study in Italy of 238 students between 11 and 14 years found that $26.3 \%$ had physically bullied others at least once during the previous three months (Baldry and Farrington, 1999). Furthermore, a study in Turkey indicated that more than one-third (35.5\%) of 692 students between $14-17$ years of age had physically bullied at least once during the academic year (Kepenekci and Cinkir, 2006). 
However, in Thailand 3,047 students from grades four to nine (P4-M3) in five regions between 1 February to 31 March 2006, a study in southern Thailand found that only $15.1 \%$ had physically bullied others at some time during the preceding two months based on interviews (Tapanya, 2006).

Many studies have reported that students start to bully at a young age, and students who are bullies tend to be bullies as adults. In addition, Totten and Quigley (2005) reported that in the vast majority of cases, the seeds of bullying behaviour and victimization are planted at home. The family is the most important socializing institution. However, they found that individual characteristics can interact with family factors to increase the likelihood that a child will be a bully or be a victim of bullying. Studies have found that family violence, ineffective parenting, parent-child conflict and sibling conflict are correlated with the development of aggression in boys and girls. Bullying behaviour is different according to family structure, social and cultural environments. Therefore, this study was initiated in order to study how domestic violence has an effect on bullying behaviour. As a matter of scientific interest we would like to know the prevalence of physical bullying and the risk factors associated with physical bullying. The result from this study may be useful for preventing bullying at school. In addition, information from bullying can be an indicator of family violence, not only personal problems but also social problems and needs to be solved urgently.

\section{Material and Methods}

\subsection{Participants}

Sample size calculations were based on the main outcome variable, which was physical bullying. The prevalence of physical bullying among students from grade four to nine in southern, Thailand was estimated to be $15.1 \%$, from Tapanya (2006). Sample size was calculated by the following formula (McNeil, 1996):

$$
\mathrm{n}=\mathrm{Z}_{\alpha / 2}^{2} \frac{\pi(1-\pi)}{d^{2}}
$$

where $Z_{\alpha / 2}$ is the critical value for the standardized normal distribution corresponding to a two-tail probability $\alpha, \pi$ is the prevalence of the outcome, and $d$ is half of the width of the 100(1- $\alpha) \%$ confidence interval. Choosing a prevalence of $15 \%$ based on previous studies and the ability to detect a difference in this prevalence of $5 \%$, with $95 \%$ confidence interval. The sample size of the study is then 244 lower secondary school students (M1-M3) in Pattani province. Both samples had approximately equal numbers of boys and girls.

\subsection{Variables}

The determinants in the study provided information on (a) characteristics of secondary school students (gender, age group, ethnicity, punishment (defined as history of punishment by parents) and school type), (b) family environments (father's occupation, mother's occupation, marital status of parents and parental violence (defined as emotional or physical violence between parents)). Physical bullying was taken as the outcome variable of interest. This outcome was measured by asking lower secondary school students whether or not they had experienced physical bullying (never bullied others or bullied others).

\subsection{Data Collection}

Primary data were collected from the selected lower secondary school students (M1-M3) in Pattani province, southern Thailand. The data for this study was collected using questionnaire method and the respondents were given a short briefing before they fill in the questionnaire. Verbal consent to participate in the study was obtained from students after assurance that confidentially of short briefing was given. Before the collected data, the purpose of this study was explained, giving assurance of anonymity and stressing the importance of answering truthfully. All participants were answer questionnaire in December 2006 by researchers at a neutral location outside the schools. The survey took approximately 5-10 minutes to complete. Relevant data were collected, verified and recorded in a separate data record form and used to investigate factors associated with physical bullying.

\subsection{Instruments for collecting data}

To collect data, a questionnaire was used in order to get information about physical bullying. The questionnaire was designed to determine the students' reported behaviour of bullying in schools. Since the topic was relatively new for Pattani province, there was no available research on which to base the construction of the research instruments. Consequently, the questions in the questionnaire were partly derived from and based on the studies by DeVoe and Kaffenberger (2005). This questionnaire used multiple choice questions and provided information on (a) characteristics of students, (b) family environments, (c) victims of bully and (d) bullying others.

Questions on bullying referred to events that occurred during 2006 in either the previous six months (1 May to 31 October, 2006) or the previous month (in November 2006) preceding the interview. Students answered by checking one or more responses. The bullying inventory measures levels of bullying and being bullied by using two key variables: In the last semester (1 May to 31 October, 2006), have you ever physically bullied other students at your school (slapped, hit, kicked, 
punched, or weapons)?, and In the last semester (1 May to 31 October, 2006), have you ever been physically bullied by other students at your school (slapped, hit, kicked, punched, or weapons)? Possible responses were "no" or "yes". If "yes", then use of a slap, hit, kick, punch, weapons or other was recorded, as well as the frequency.

\subsection{Statistical Methods}

Statistics for descriptive analysis include percentages for measuring prevalence of bullying. The associations between the outcome and the determinant variables were examined in the preliminary analysis. All of the variables in the study were categorical and therefore chi-squared statistics and 95\% confidence intervals were used to describe these associations. Logistic regression was used to model the association between the bullying and the determinants.

\section{Results}

\subsection{Prevalence of physical bullying}

Nearly one in five (18.5\%) students reported that they had physically bullied another student during either the previous six months or during the previous month.

\subsection{Logistic Regression Models}

The results after fitting a logistic regression model to the data with all determinants included, and then reducing the model by eliminating determinants with overall $\mathrm{p}$-values greater than 0.05 , using backward elimination. It was found that four variables, age group, ethnicity, school type and parental violence were all associated with physical bullying in Pattani province, after adjusting for the other determinants.

\section{Conclusions and Discussion}

\subsection{Conclusions}

This research studied the prevalence and predictors of physical bullying among lower secondary school students (M1-M3) in Pattani province, southern Thailand. The prevalence of physical bullying during both the preceding six months and during the previous month was found to be $18.5 \%$ (95\% CI: 13.6-23.4).

This study found that the four factors, age group, ethnicity, school type and parental violence are positively associated with physical bullying.

Students aged 14 years or over were more likely to physically bully others compared to those aged less than 14 years. These results are similar to those found by Woods and White (2005) in England and Pereira et al. (2004) in Portugal. They found that older and often stronger students tended to bully others.

Thai students were more likely to physically bully others compared to students of Malay or Chinese ethnicity. This result is not consistent with previous studies. Many studies have reported a difference of bullying among ethnic groups, such as white students $(3.5 \%)$ were more likely to being directly bullied than black students $(2.6 \%)$ (DeVoe and Kaffenberger, 2005). In contrast to a study in South Africa, ethnicity was not significantly associated with bullying others (Greeff, 2004). The explanation for this may be due to the difference of samples, cultural differences, and definitions of bullying.

Our study found that students who had witnessed physical violence between their parents were more likely to bully others compared to those who had never witnessed physical violence. Exposure to parental violence is related to negative behaviour of students. Other studies (Totten and Quigley, 2005; Ahmed and Braithwaite, 1996; Craig et al., 1998; Stevens et al., 2002) reported that students who bullied tend to come from violence families, negative emotional attitudes (e.g., lack of warmth, more conflict, punishment and a less close relationship with their parents). In addition, students who came from urban schools were approximately 4 times more likely to physically bully others than were those from rural schools.

This study provides some directions for attempting to reduce the problems of bullying. It might be useful if teachers and other authorities assist parents to reduce their own level of family violence as a way of helping their children. Furthermore, action in urban areas and especially among those of Thai ethnicity seems to be more urgent than in rural areas and among other ethnic groups.

\subsection{Discussion}

This study showed that bullying is a problem among lower secondary school students (M1-M3) in Pattani province, southern Thailand. The author found that the prevalence of physical bullying was $18.5 \%$ (95\% CI: 13.6-23.4). Gender was not significantly associated with bullying others (boys $=18.7 \%$, girls $=18.2 \%$ ). Similar to results from other countries, we concluded that there are differences in rates of bullying among individuals from different family environment. Moreover, our study suggests that besides family environment, factors such as age group, ethnicity, and school type are important risk factors for bullying others, which remain significant after multivariable adjustment. In addition, the author found that most of the bullying students admitted having witnessed physical violence from their 
parents. Therefore, in this study confirm the research hypothesis that students who had experience of parental violence are more likely to be bullies at school.

In southernmost of Thailand specifically, it is important that Pattani province should consider school bullying as a serious problem, and be aware that it has negative consequences on students' psychological health as well as on their school achievement (Totten and Quigley, 2005).

\section{Limitations and recommendation}

There are some limitations to the current study. The sample selection was based on the convenience technique therefore, the subjects may not represent all lower secondary school students in Pattani province. If further research is done in this area, stratified random sampling method should be used to get a sample were representative of the target population.

\section{Acknowledgements}

The authors would like to express our sincere gratitude and deep appreciation to Professor Don McNeil and Dr. Greig Rundle for their helpful suggestions.

\section{References}

Ahmed, E. and Braithwaite, V. (1996). A multiperspective comparison of bullying status groups: Family and School concerns. The Oxford University Press.

Baldry, A.C. and Farrington, D.P. (1999). Types of bullying among Italian school children. Journal of Adolescence, 22, 423-426.

Craig, W.M., Peters, R.D. and Konarski, R. (1998). Bullying and Victimization Among Canadian School Children. Applied Research Branch Strategic Policy, Human Resources Development Canada.

DeVoe, J.F. and Kaffenberger, S. (2005). Student Reports of Bullying: Results from the 2001 School Crime Supplement to the National Crime Victimization Survey (NCES 2005-310). U.S. Department of Education, National Center for Education Statistics, Washington, DC:U.S. Government Printing Office.

Greeff, P. (2004). The Nature and Prevalence of Bullying during the Intermediate School Phase. [Online] Available: http://www.etd.uovs.ac.za/ETD-db//theses/available. (October 18, 2006).

Kepenekci, Y.K. and Cinkir, S. (2006). Bullying among Turkish high school students. Child Abuse \& Neglect, 30, 193-204.

McNeil, D. (1996). Epidemiological Research Methods. New York. John Wiley and Sons Ltd.

Pereira, B., Mendonca, D., Neto, C., Valente, L. and Smith, P.K. (2004). Bullying in Portuguese Schools. School Psychology International, 25(2): 241-254.

Sampson, R. (2002). Bullying is Schools. Problem-Oriented Guides for Police Series, 12.

Stevens, V., Bourdeaudhuij, I.D. and Oost, P.V. 2002. Relationship of the Family Environment to Children's Involvement in Bully/Victim Problems at School. Journal of Youth and Adolescence, 31(6), 419-428.

Tapanya, S. (2006). Bullying Among Thailand School Student. [Online] Available: http://www.thaihealth.or.th (October 18, 2006).

Totten, M. and Quigley, P. (2005). Parental knowledge of child-reported bully-victim And sexual harassment problems in seven Canadian schools: Implications for policy and program development. Canadian Public Health Association.

Wong, D.S.W. (2004). School Bullying and Tackling Strategies in Hong Kong. International Journal of Offender Therapy and Comparative Criminology, 48(5), 537-553.

Woods, S. and White, E. (2005). The association between bullying behaviour, arousal levels and behaviour problems. Journal of Adolescence, 28, 381-395.

Table 1. Associations between physical bullying and categorical determinants

\begin{tabular}{ccccc}
\hline & $\begin{array}{c}\text { All } \\
\text { Students } \\
(\mathrm{n}: 244)\end{array}$ & Bullying & Not bullying & \\
& $\mathrm{n}$ & $\%$ & $\%$ & $\mathrm{p}$-value \\
\hline Gender & & & & 0.937 \\
Boys & 118 & 48.9 & 48.2 & \\
Girls & 126 & 51.1 & 51.8 &
\end{tabular}




\section{Age group}

12-13 years

$14+$ years

Ethnicity

Malay or Chinese

Thai

Punishment

Yes

No

\section{School type}

Urban

Rural

Father's occupation

Business/Government

Employee

Other

Mother's occupation

Business/Government

Employee

Other

Marital status of parents

Married

Other

Parental violence

Never

Emotional violence

Physical violence

\section{0}

154

189
0.000

42.2

57.8

0.020

80.4

19.6

24.6

75.4

0.007

$82.2 \quad 61.3$

$\begin{array}{ll}17.8 & 38.7\end{array}$

0.763

38.7

36.2

25.1

0.979

39.2

37.2

23.6

$77.8 \quad 83.4$

$22.2 \quad 16.6$

0.003

The characteristics of students are shown in Table 1. Participants in this present study consisted more than half (51.6\%) of the students were girls. All students were categorized into one of the age groups: $12-13$ years (36.9\%) and 14 years or above (63.1\%). With respect to their ethnicity, most students (77.5\%) were of Malay or Chinese ethnicity. The majority $(76.6 \%)$ of the students reported never having been punished by their parents, although $23.4 \%$ of students reported that they had been punished by parents so severely that they would never forget it. Nearly two-thirds $(65.2 \%)$ of students came from schools in the Pattani urban area.

More than one-third (39.3\%) of fathers were business or government employees and so were a similar percent of mothers. $36.5 \%$ of fathers were employees in private businesses and the rest were categorized as "other", which included unemployed. For the determinant "mother's occupation", more than one-third (36.9\%) were employees in private businesses and the rest were categorized as "other", which includes unemployment and housewives. Most parents $(82.4 \%)$ were married. Overall, $61.9 \%$ of all students had never witnessed violence from their parents, whereas $26.2 \%$ of the students admitted having witnessed emotional violence between parents and a further $11.9 \%$ admitted having witnessed physical violence between their parents.

Since all of the variables are categorical, Pearson's chi-squared test was used to determine the association in each case. Table 1 shows that the variables most statistically significantly were age group, ethnicity, school type and parental violence, respectively. Students aged 14 years or over reported their bullying of others at higher rates than did younger students $(p=0.000)$. Ethnicity was positively associated with bullying, with students of Thai ethnicity being more likely to bully than students of either Malay or Chinese ethnicity at least from the data in this study $(p=0.020)$. This research, students were more likely to bully if they had witnessed family violence between their parents $(\mathrm{p}=0.003)$. The data 
showed that students who came from urban schools were more likely to bully than students from rural schools $(\mathrm{p}=0.007)$.

Table 2. Model of association between determinants and bullying others

\begin{tabular}{|c|c|c|c|}
\hline Determinants & OR & $(95 \% \mathrm{CI})$ & $\mathrm{p}$-value \\
\hline $\begin{array}{l}\text { Age group } \\
\begin{array}{l}12-13 \text { years } \\
14+\text { years }\end{array}\end{array}$ & 6.8 & $(2.6,17.7)$ & 0.000 \\
\hline $\begin{array}{l}\text { Ethnicity } \\
\text { Malay or Chinese } \\
\text { Thai }\end{array}$ & 2.7 & $(1.2,6.0)$ & 0.015 \\
\hline $\begin{array}{l}\text { School type } \\
\text { Rural } \\
\text { Urban }\end{array}$ & 4.2 & $(1.8,10.1)$ & 0.001 \\
\hline $\begin{array}{l}\text { Parental violence } \\
\qquad \begin{array}{l}\text { Never } \\
\text { Emotional violence } \\
\text { Physical violence }\end{array}\end{array}$ & $\begin{array}{l}0.8 \\
3.4\end{array}$ & $\begin{array}{l}(0.4,2.0) \\
(1.3,9.0)\end{array}$ & 0.028 \\
\hline
\end{tabular}

Table 2 shows that the students aged 14 years or over were more likely to physically bully others than those aged less than 14 years, by a factor of 6.8 (95\% CI: 2.6-17.7). Thai ethnicity students were 2.7 times (95\% CI: $1.2-6.0)$ more likely to physically bully others than were those of Malay or Chinese ethnicity. In addition, students who came from urban schools were 4.2 times (95\% CI: 1.8-10.1) more likely to physically bully others than those from rural schools. Furthermore, students who reported having witnessed physical violence from their parents were 3.4 times $(95 \%$ CI: 1.3-9.0) more likely to physically bully others than those who never witnessed physical violence, while students who admitted having witnessed emotional violence from their parents were 0.8 times (95\% CI: $0.4-2.0)$ more likely to physically bully others than those who never witnessed emotional violence.

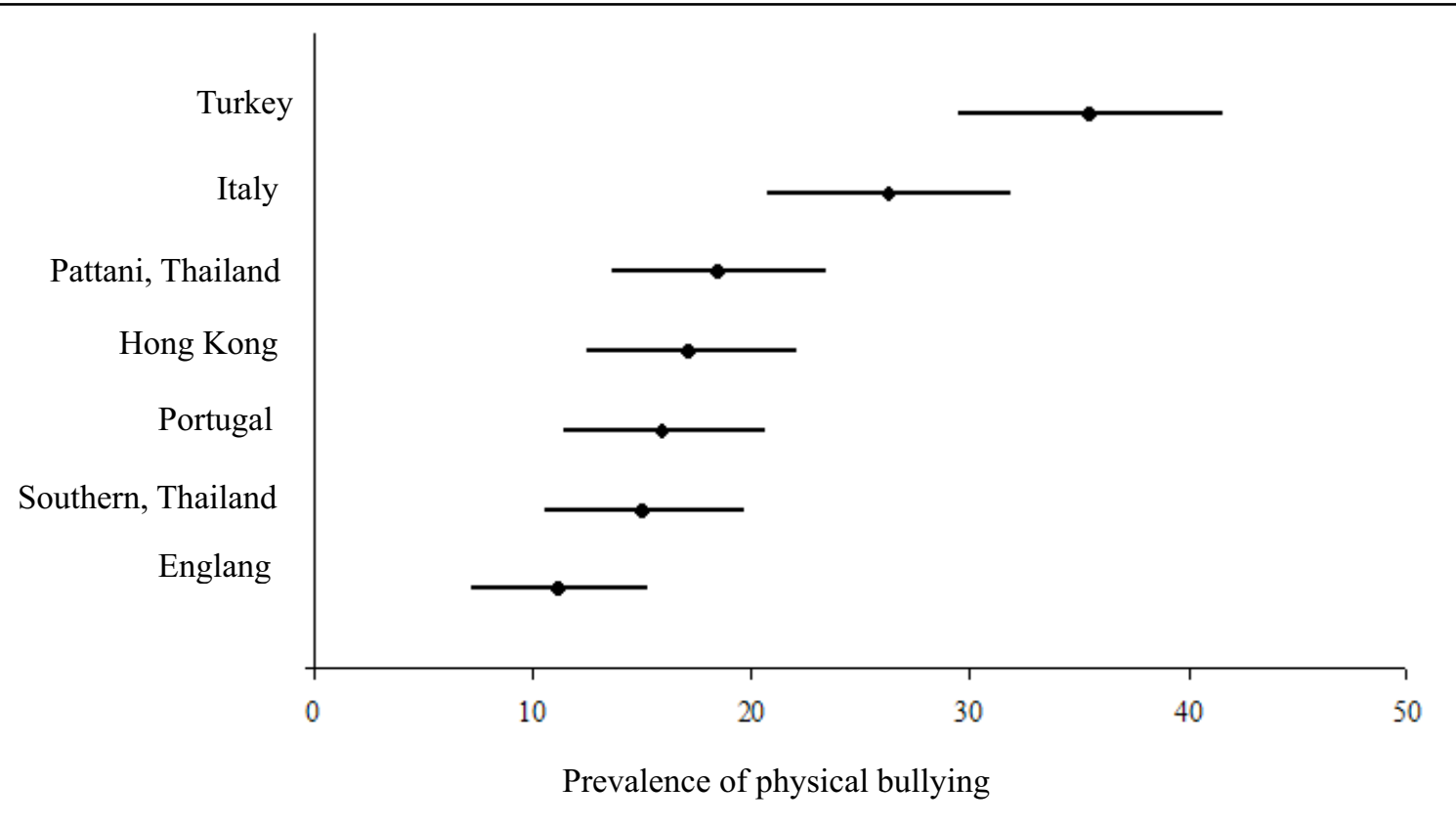

Figure 1. Comparison of the prevalence for physical bullying 
Figure 1 shows a comparison of the prevalence for bullying others in the current study with previous studies. Results from this study were not much different from most other studies. However, a study in Turkey indicated that the prevalence of bullying others was much higher with 35.5\% (CI: 29.5-42.0) (Kepenekci and Cinkir, 2006).

The estimated prevalence of physical bullying in school seems to depend on the study design, definitions of bullying, and cultural differences. However, there are many causes of bullying that are not only related to the individual, but also to the socio-family environment. 